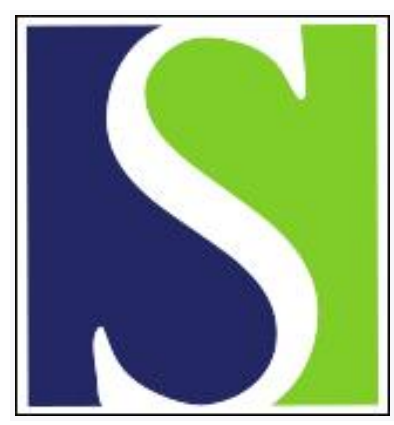

Scand J Work Environ Health 1999;25(5):450-456

https://doi.org/10.5271/sjweh.459

Issue date: Oct 1999

Risk of hand dermatitis among hairdressers versus office workers

by Uter W, Pfahlberg A, Gefeller O, Schwanitz HJ

Key terms: atopy; epidemiology; logistic regression analysis; occupational skin disease; wet work

This article in PubMed: www.ncbi.nlm.nih.gov/pubmed/10569466

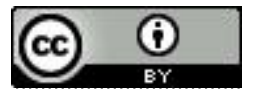




\title{
Risk of hand dermatitis among hairdressers versus office workers
}

\author{
by Wolfgang Uter, MD, ${ }^{1}$ Annette Pfahlberg, PhD, ${ }^{2}$ Olaf Gefeller, PhD, ${ }^{2}$ Hans J Schwanitz, $M D^{\prime}$
}

\begin{abstract}
Uter W, Pfahlberg A, Gefeller 0, Schwanitz HJ. Risk of hand dermatitis among hairdressers versus office workers. Scand J Work Environ Health 1999;25(5):450-456.

Objectives The risk of irritant skin damage associated with hairdressing was estimated with the individual occupational exposure and other relevant factors having been taken into consideration.

Methods A cohort of 2352 hairdressing and 111 office apprentices was prospectively followed for the duration of their vocational training ( 3 years), 3 examinations having been made and 3 years of recruitment having been used [1992 (hairdressers only), 1993, 1994] in 15 vocational training schools in northwest Germany. The information of the final follow-up examination was used for the analysis.

Results A multifactorial analysis taking several (constitutional) risk factors, which were unevenly distributed between the 2 groups, into account revealed a significantly increased risk for hairdressers when compared with office workers (odds ratio approximately 4.0) with a marked decline in the most recently recruited (1994) apprentice group. Other significant factors increasing the dermatitis risk were (i) low ambient absolute humidity, (ii) young age, and (iii) a certain higher range of "atopy score". If the individual profile of occupational exposure among hairdressers was also considered, unprotected wet work of more than 2 hours per day was found to be a significant risk factor.
\end{abstract}

Conclusions Good skin protection, as operationalized in the present study, can diminish, but not eliminate, the risk of occupational irritant hand dermatitis among hairdressers.

Key terms atopy, epidemiology, logistic regression analysis, occupational skin disease, wet work.

Irritant skin damage due to work with wet hands is a serious concern in several occupations, particularly in the hairdressing trade. In this occupational setting, not only wetness, but also a variety of detergents and other potentially irritating constituents of hair care products can damage exposed hands. Apprentices are particularly at risk, because they often carry the main load of unqualified wet tasks like shampooing (1) when compared with trained hair stylists (2). Irritant hand dermatitis, which can be aggravated by allergic contact sensitization at some stage, and also primary allergic contact dermatitis can result in significant morbidity and may even necessitate a change in job. Job careers such as these have a considerable socioeconomic impact on the population level. On the individual level, they lead to the burden of a possibly chronic disease and the sacrifice of giving up a job of choice. Under these circumstances, improved primary prevention is extremely important.

Studies of different design (references 3-5 among others) and, in particular, preliminary analyses from the present cohort study POSH (Prevention of Occupational Skin Disease in Hairdressers) have already indicated the importance of unprotected wet work, constitutional risk factors, and other (eg, environmental) factors $(1,6,7)$. Previous analyses of the POSH study referred to an internal reference group of hairdressing apprentices who protected themselves relatively well according to preventive guidelines in force in Germany since September 1992 (8). These data have demonstrated that in all stages of the study unprotected wet work approximately doubled the odds of skin damage and, accordingly, that good skin protection resulted in significant risk reduction. However, these analyses could not address the risk inherent in this occupation even with good protection and the effects of possible exposure misclassification due to the use of an inevitably rather crude self-administered questionnaire instrument. Therefore, the inclusion of an external reference group of office apprentices, who had been prospectively followed in an identical fashion (9), appeared useful to obtain a realistic estimate of the risk

1 University of Osnabrück, Department of Dermatology, Environmental Medicine and Health Theory, Osnabrück, Germany.

2 University of Erlangen, Institute of Medical Informatics, Biometry and Epidemiology, Erlangen, Germany.

Reprint requests to: Dr Wolfgang Uter, University of Osnabrück, Department of Dermatology, Environmental Medicine and Health Theory, D-49069 Osnabrück, Germany. [E-mail: wuter@1z.uni-osnabrueck.de] 
associated with hairdressing. This paper describes the findings of the comparison between hairdressers and office apprentices regarding the risk of hand dermatitis based on the data of the POSH study at the final followup examination.

\section{Subjects and methods}

The prospective cohort study POSH was carried out in vocational training schools in 15 cities in northwest Germany, where hairdressing apprentices had been examined soon after the start of their training (a preemployment examination was rarely possible for logistic reasons) in the summer of 1992, 1993 and 1994, after an informed consent had been obtained from the participants or their parents, if the participants were under age (ie, younger than 18 years of age). Follow-up examinations were scheduled at the end of the first year and after 3 years (at the end of the training).

Altogether 2352 hairdressing apprentices and 111 office workers (trainees) were recruited for this study. A high dropout rate is characteristic for this young and mobile age group; altogether $48.2 \%$ of all the initially recruited hairdressing apprentices and $61.3 \%$ of the office trainees underwent a final examination. Point and period prevalences of the outcome of interest in both cohorts are shown in table 1 , together with the respective incidence rates relating new occurrences to the cumulated person-time at risk of the study participants. Analyses of the office cohort (9) and the hairdressing cohort $(6,7,11)$ have been published previously; the following paper will focus on a comparison between the 2 cohorts based on prevalence data at the stage of final follow-up, employing a multifactorial analysis.

During the initial examination, a short self-administered questionnaire relating to family and personal history (atopy, intolerances), leisure activities and specific tasks, and skin protection at work was checked by the observer, who also recorded physical findings on a standardized form (1). Operational definitions for skin changes of the hands have been employed for standardization and for modeling the outcome variable (9). In addition to important anamnestic items relating to atopy (ie, past flexural eczema and past hand dermatitis) several atopic signs were documented and operationalized in an "atopy score" according to Diepgen et al (10). During the follow-up examinations, skin changes of the hands were documented and the history since the last examination (skin symptoms, medical consultations, sick leave, etc) was recorded, together with current occupational and leisure-time exposures, the latter again including wet cleaning work, minding of children under 6 years of age, gardening, and decoration work.

The individual spectrum of occupational tasks, skin protection, cleansing, and skin care was recorded using a standardized questionnaire; a slightly modified and extended version is available now at the internet address "http://www.agw.uni-osnabrueck.de/derma/frisbrit.htm". From these data, the individual average duration of unprotected wet work and of glove-protected work per day was approximatively calculated (6).

Participation in the study was additionally offered to all office apprentices attending a vocational training school in Osnabrück in their first year of training, including 2 subcohorts of apprentices, one commencing in August 1993 and the other in August 1994 (9). This occupational group was followed in an identical fashion, however, without the recording of occupational exposure (because there was none with a potential for skin irritation).

Low ambient absolute humidity had been found to be significantly associated with the occurrence of irritant skin changes of the hands in a previous analysis of 2 hairdressing subcohorts (7). Thus relevant meteorological parameters were obtained from the German Meterological Service (Deutscher Wetterdienst) for inclusion in the multivariate analysis. These parameters included mean values of ambient day temperature $\left({ }^{\circ} \mathrm{C}\right)$ and relative humidity (\%) on the days and places of examination; the respective values of absolute humidity ( $\mathrm{mg} / \mathrm{l})$ were calculated from these parameters (7).

In the modeling of the outcome variable, the presence of any irritant skin changes was deliberately conceived

Table 1. Epidemiologic measures of morbidity used for the cohort of office and hairdressing apprentices. Only the point prevalences and incidence are based on dermatological findings; the period prevalences (period = duration of the study) include anamnestic data. [See also the text and reference 11 .] $(95 \% \mathrm{Cl}=95 \%$ exact confidence intervals)

\begin{tabular}{|c|c|c|c|c|c|c|c|c|c|c|c|c|c|}
\hline \multirow[t]{2}{*}{ Group } & \multicolumn{3}{|c|}{ Examination 1} & \multicolumn{3}{|c|}{ Examination 2} & \multicolumn{3}{|c|}{ Examination 3} & \multirow{2}{*}{$\begin{array}{l}\text { Period } \\
\text { preva- } \\
\text { lence }\end{array}$} & \multirow{2}{*}{$\begin{array}{c}95 \% \mathrm{Cl} \\
\text { for } \\
\text { period } \\
\text { preva- } \\
\text { lence }\end{array}$} & \multirow{2}{*}{$\begin{array}{c}\text { Inci- } \\
\text { dence } \\
\text { (per } 100 \\
\text { persons } \\
\text { per year) }\end{array}$} & \multirow{2}{*}{$\begin{array}{c}95 \% \mathrm{Cl} \\
\text { for } \\
\text { inci- } \\
\text { dence }\end{array}$} \\
\hline & $\mathrm{N}$ & $\begin{array}{l}\text { Point } \\
\text { preva- } \\
\text { lence }^{\mathrm{a}}\end{array}$ & $95 \% \mathrm{Cl}$ & $N$ & $\begin{array}{l}\text { Point } \\
\text { preva- } \\
\text { lence }^{3}\end{array}$ & $95 \% \mathrm{Cl}$ & N & $\begin{array}{l}\text { Point } \\
\text { preva- } \\
\text { lence }\end{array}$ & $95 \% \mathrm{Cl}$ & & & & \\
\hline $\begin{array}{l}\text { Hairdressers } \\
\text { Office workers }\end{array}$ & $\begin{array}{r}2352 \\
111\end{array}$ & $\begin{array}{l}35.4 \\
18.9\end{array}$ & $\begin{array}{l}33.5-37.4 \\
12.1-27.4\end{array}$ & $\begin{array}{r}1717 \\
40\end{array}$ & $\begin{array}{l}47.5 \\
32.5\end{array}$ & $\begin{array}{l}45.1-49.9 \\
18.6-49.1\end{array}$ & $\begin{array}{r}1134 \\
68^{\circ}\end{array}$ & $\begin{array}{l}55.1 \\
25.0\end{array}$ & $\begin{array}{l}52.2-58.0 \\
15.3-37.0\end{array}$ & $\begin{array}{l}70.7 \\
44.1\end{array}$ & $\begin{array}{l}68.8-72.5 \\
34.7-53.8\end{array}$ & $\begin{array}{l}34.3 \\
18.4\end{array}$ & $\begin{array}{l}31.8-37.2 \\
11.6-29.3\end{array}$ \\
\hline
\end{tabular}

a Of "skin changes (any degree)". c|ncreasing sample size due to structure of cohort. [See reference 9.]

'Uter et al, 1998 (9). 
as a (relatively soft) definition of a case [of "skin changes (any degree)"] (9). Other, more conservative case definitions had also been used previously; their effect on estimates of prevalence (11) and constitutional risk factors (6) has been outlined in the respective papers.

For comparisons between groups concerning the distribution of a categorical or continuous variable, Fisher's exact test and the Wilcoxon-Mann-Whitney test were used, respectively. A logistic regression analysis was employed to quantify the independent influence of several factors on the risk for "skin changes (any degree)" with the effects of other important factors controlled for. The appropriateness of the specific logistic model was checked by the goodness-of-fit statistic developed by Hosmer \& Lemeshow (12). The results of the logistic analyses are reported as odds ratios (OR), quantifying the degree of association between the exposure and the outcome variable, and their accompanying $95 \%$ confidence intervals $(95 \% \mathrm{CI})$ have been computed by the profile likelihood method. Due to the high prevalence of the outcome, the odds ratio cannot be regarded as a valid approximation of relative risk. However, it is a standard epidemiologic measure in its own right with which to quantify the association between potential risk factors and outcome, enabling a comparison of our results with those of other studies. The statistical analyses were performed with the program package SAS (Statistical Analysis System, version 6.12, SAS Institute, Cary, NC).

\section{Results}

The distribution of the important parameters included in the multifactorial model for the 2 subcohorts is shown in table 2 , supplemented by a comparison with the prevalence of these factors in the initial cohort $(\mathrm{N}=2352$ and 111 , respectively). When the 2 groups were compared, any attribute of atopy (eg, previous hand or flexural dermatitis or a high atopy score) was found to be more frequent in the group of office apprentices than among the hairdressers. This difference was significant for the atopy score, both for the cohort initially recruited and for the subset followed to the end of the study $(\mathrm{P}<0.0001$ in both cases). When the distribution of these parameters was compared between the subset of dropouts versus participants followed to the end of the study, a significant difference was noted only for the atopy score of the hairdressing group $(\mathrm{P}<0.0001)$ in the sense of a lower average value of the score in the group remaining under observation. This finding indicates a selective dropout of hairdressing apprentices with a distinct atopic constitution. Furthermore, the hairdressing apprentices were significantly younger $(\mathrm{P}<0.0001$ for uncategorized data). The vast majority of the examinations had been performed by one observer (WU) for both groups $(83.8 \%$ and $72.8 \%$, respectively); other observers took part in different years and to a varying degree. Office apprentices were exposed to a low ambient humidity to a less extent than the hairdressing apprentices; in particular, none to less than $5 \mathrm{mg} / \mathrm{l}$.

\section{Multivariable analysis}

The following analyses were based on data from all the participants in the final examinations of both groups (ie, 1134 hairdressing and 68 office trainees). The results of a first logistic regression analysis relating the outcome (mild-to-severe skin changes of the hands) to several explanatory variables included in the model are presented in table 3. When compared with the 1993 period for the

Table 2. Prevalence of various (risk) factors for the subcohort of office apprentices versus hairdressing apprentices, final examination and partial initial examination for analyzing selective dropout.

\begin{tabular}{|c|c|c|c|c|c|c|}
\hline \multirow[t]{3}{*}{ Current factors } & \multicolumn{4}{|c|}{ Prevalence (\%) } & \multicolumn{2}{|c|}{ Statistical comparisons } \\
\hline & \multicolumn{2}{|c|}{ Office workers } & \multicolumn{2}{|c|}{ Hairdressers } & \multirow{2}{*}{$\begin{array}{l}\text { Examination } 1 \\
\text { (hairdressers) } \\
\text { versus ofice } \\
\text { workers } \\
\text { (P-value) }\end{array}$} & \multirow{2}{*}{$\begin{array}{l}\text { Hairdressing } \\
\text { participants } \\
\text { followed-up versus } \\
\text { dropped out } \\
\text { (P-value) }\end{array}$} \\
\hline & $\begin{array}{l}\text { Examination } 1 \\
\qquad(\mathrm{~N}=111)\end{array}$ & $\begin{array}{l}\text { Examination } 3 \\
\quad(N=68)\end{array}$ & $\begin{array}{l}\text { Examination } 1 \\
\qquad(N=2352)\end{array}$ & $\begin{array}{l}\text { Examination } 3 \\
(N=1134)\end{array}$ & & \\
\hline Age $\leq 18$ years (at recruitment) & 43.2 & 48.5 & 79.7 & 81.7 & $<0.0001$ & 0.03 \\
\hline $\begin{array}{l}\text { Absolute humidity } \leq 10.0 \mathrm{mg} / \mathrm{l} \\
\text { Constitutional factors }\end{array}$ & 100.0 & 54.4 & 26.6 & 79.5 & $<0.0001$ & - \\
\hline Atopy score (points), mean & 8.9 & 9.1 & 5.9 & 5.6 & $<0.0001$ & 0.0003 \\
\hline $\begin{array}{l}\text { Atopy score (points), classes } \\
0-3 \\
>3-5 \\
>5-7 \\
>7-9.5 \\
>9.5\end{array}$ & $\begin{array}{r}6.4 \\
8.1 \\
18.9 \\
28.8 \\
37.8\end{array}$ & $\begin{array}{r}5.8 \\
7.4 \\
20.6 \\
25.0 \\
41.2\end{array}$ & $\begin{array}{l}26.4 \\
20.6 \\
20.9 \\
17.6 \\
14.5\end{array}$ & $\begin{array}{l}29.5 \\
21.1 \\
20.2 \\
16.8 \\
12.4\end{array}$ & & \\
\hline Past flexural eczema & 15.3 & 11.8 & 7.5 & 7.1 & 0.006 & 0.48 \\
\hline Past hand dermatitis (including pompholyx) & 13.5 & 10.3 & 9.2 & 8.6 & 0.13 & 0.36 \\
\hline Male gender & 23.4 & 20.6 & 6.1 & 5.4 & $<0.0001$ & 0.20 \\
\hline
\end{tabular}


office trainees as a reference group, (i) the next period for the office workers showed little difference, (ii) the first 2 hairdresser periods had significantly elevated odds ratios of $4.3(95 \% \mathrm{CI} 1.8-11.1)$ and $4.3(95 \% \mathrm{CI} 1.9-$ 10.5), while (iii) the last period for the hairdressers showed a somewhat lower odds ratio of 2.4 (95\% CI $1.1-6.0)$. This decline in the odds ratios for the hairdressers was statistically significant $(\mathrm{P}<0.001)$.

An age of 18 years or less - dominating in the hairdressing group (table 2) — was associated with a significantly increased risk for irritant skin changes, while male gender showed only a weak tendency of being a risk factor.

In contrast to analyses of findings during the first year of training (1), previous flexural or hand dermatitis was not associated with an increased risk of skin changes in the final follow-up examination. Only a rare combination of both factors showed a tendency of being a risk factor (OR 1.6, 95\% CI 0.5-5.9). While an elevated atopy score of $7-9.5$ points was found to be a significant risk factor, the highest score category ( $\leq 10$ points) showed a striking decline in risk.

A previous, preliminary observation concerning the association between low absolute humidity and the occurrence of irritant skin damage (7) was confirmed in an analysis comprising the whole cohort when a dichotomous variable, corresponding to the cutpoint of the reference group in reference 7 (ie, a value of $\leq 10 \mathrm{mg} / \mathrm{l}$ ), was used.

While in the primary model occupational exposure was summarized for the period-specific hairdressing attributes, an alternative model also included several exposure-related factors, for example, a combination of daily wet and glove work in 4 categories, hand washing, and the application of cream in the salon (these variables were all set at zero for the office trainees). The results of this alternative analysis are shown in table 4.

With respect to occupational exposure, wet work for more than 2 hours proved to be a significant risk factor. Frequent application of emollients showed a tendency of being a protective factor. Other factors already included in the primary model showed little change in the respective risk estimates, except a considerable decline in the risk associated with the occupation and time period attribute (table 4). In a further analytic step of the modelbuilding process, possible interactions between occupational exposure (wet work and glove wearing) and the time period attribute were addressed. In this analysis no significant interaction was found, and therefore an overall relatively stable dose-response pattern was indicated for occupational exposure and dermatitis risk.

The results of the Hosmer \& Lemeshow goodnessof-fit test indicated an acceptable model fit for the models shown in table 3 and $4(\mathrm{P}=0.43$ and $\mathrm{P}=0.50$, respectively).
Table 3. Results of the multiple logistic regression analysis $(\mathrm{N}=1202)$, primary model summarizing occupational exposure variables in the hairdressing attribute of the waves; also controlled for observers. $(\mathrm{OR}=$ odds ratio, $95 \% \mathrm{Cl}=$ profile likelihood confidence limits)

\begin{tabular}{lccc}
\hline & $\begin{array}{c}\text { Prevalence of } \\
\text { risk factors } \\
(\%)\end{array}$ & \multicolumn{2}{c}{$\begin{array}{c}\text { "Skin changes" } \\
\text { (prevalence } \\
53.4 \%)\end{array}$} \\
\cline { 2 - 4 } & & OR & $95 \% \mathrm{Cl}$ \\
\cline { 2 - 4 } & 2.9 & 1.0 & (reference) \\
Office workers, 1993 & 2.7 & 1.0 & $0.3-3.3$ \\
Office workers, 1994 & 25.0 & 4.3 & $1.8-11.1$ \\
Hairdressers, 1992 & 36.8 & 4.3 & $1.9-10.5$ \\
Hairdressers, 1993 & 32.6 & 2.4 & $1.1-6.0$ \\
Hairdressers, 1994 & 6.2 & 1.3 & $0.8-2.2$ \\
Male gender & 80.2 & 1.6 & $1.2-2.2$ \\
Age $\leq 18$ & 7.3 & 1.1 & $0.7-1.7$ \\
Past flexural eczema & & & $0.7-1.6$ \\
Past hand dermatitis & 8.7 & 1.0 & 0.7 \\
(including pompholyx) & & & \\
Atopy score & 28.2 & 1.0 & $($ reference) \\
0-3 & 20.3 & 1.0 & $0.7-1.4$ \\
$>3-5$ & 17.2 & 1.3 & $0.9-1.9$ \\
$>5-7$ & 14.1 & 1.1 & $1.2-2.6$ \\
$>7-9.5$ & 78.0 & 1.8 & $1.3-2.4$ \\
$>9.5$ & & &
\end{tabular}

a Hosmer and Lemeshow goodness-of-fit statistic $=8.00(P=0.43)$

Table 4. Results of a multiple logistic regression analysis $(\mathrm{N}=1202)$, alternative, full model, also controlled for observers. (OR $=$ odds ratio, $95 \% \mathrm{Cl}=$ profile likelihood confidence limits)

\begin{tabular}{|c|c|c|c|}
\hline & \multirow[t]{2}{*}{$\begin{array}{c}\text { Prevalence } \\
\text { of risk } \\
\text { factors } \\
(\%)\end{array}$} & \multicolumn{2}{|c|}{$\begin{array}{c}\text { "Skin } \\
\text { changes" } \\
\text { (prevalence } \\
53.4 \% \text { ) }\end{array}$} \\
\hline & & OR & $95 \% \mathrm{Cl}$ \\
\hline Office workers, 199'93 & 2.9 & 1.0 & (reference) \\
\hline Office workers, 1994 & 2.7 & 1.1 & $0.3-3.3$ \\
\hline Hairdressers, 1992 & 25.0 & 3.1 & $1.2-8.2$ \\
\hline Hairdressers, 1993 & 36.8 & 3.1 & $1.3-8.1$ \\
\hline Hairdressers, 1994 & 32.6 & 1.7 & $0.7-4.4$ \\
\hline Male gender & 6.2 & 1.3 & $0.8-2.2$ \\
\hline Age $\leq 18$ & 80.2 & 1.6 & $1.1-2.1$ \\
\hline Past flexural eczema & 7.3 & 1.1 & $0.7-1.7$ \\
\hline $\begin{array}{l}\text { Past hand dermatitis } \\
\text { (including pompholyx) }\end{array}$ & 8.7 & 1.1 & $0.7-1.8$ \\
\hline $\begin{array}{l}\text { Atopy score } \\
\qquad \begin{array}{l}0-3 \\
>3-5 \\
>5-7 \\
>7-9.5 \\
>9.5\end{array}\end{array}$ & $\begin{array}{l}28.2 \\
20.3 \\
20.2 \\
17.2 \\
14.1\end{array}$ & $\begin{array}{l}1.0 \\
1.0 \\
1.3 \\
1.8 \\
1.1\end{array}$ & $\begin{array}{c}\text { (reference) } \\
0.7-1.4 \\
0.9-1.9 \\
1.2-2.6 \\
0.7-1.6\end{array}$ \\
\hline Wet work $^{b}<2 \mathrm{~h}$ and glove wearing $\mathrm{b} \geq 2 \mathrm{~h}$ & 15.5 & 1.0 & (reference) \\
\hline Wet work $^{b}<2 \mathrm{~h}$ and glove wearing ${ }^{b}<2 \mathrm{~h}$ & 1.3 & 1.4 & $0.5-4.3$ \\
\hline Wet work ${ }^{b} \geq 2 \mathrm{~h}$ and glove wearing $\mathrm{b}^{\mathrm{b}} \geq 2 \mathrm{~h}$ & 46.8 & 1.6 & $1.1-2.3$ \\
\hline Wet $^{\text {work }}{ }^{b} \geq 2 \mathrm{~h}$ and glove wearing $\mathrm{b} \leq 2 \mathrm{~h}$ & 30.7 & 1.8 & $1.2-2.6$ \\
\hline Handwashing (minimum 10 times/day) ${ }^{b}$ & 50.4 & 1.1 & $0.9-1.4$ \\
\hline $\begin{array}{l}\text { Application of cream } \\
\text { (minimum } 5 \text { times/day) }\end{array}$ & 54.5 & 0.8 & $0.6-1.0$ \\
\hline Absolute humidity $\leq 10.0 \mathrm{mg} / \mathrm{l}$ & 78.0 & 1.8 & $1.3-2.4$ \\
\hline
\end{tabular}

a Hosmer and Lemeshow goodness-of-fit statistic $=7.39(P=0.50)$.

b For office workers all classes $=0$. 


\section{Discussion}

The POSH study was the first prospective study comparing dermatitis risk between 2 occupational groups - one a typical "wet work" occupation and the other without irritant exposure - documented and followed in an identical manner. In a first analytic step, a significantly increased risk has been found for hairdressers when compared with office workers, with an interesting decline in risk for the hairdresser apprentices most recently included in the study. As the external reference group was relatively small, the precision of the risk estimates was, admittedly, not very high.

In a second step, the occupational exposure of the hairdressing apprentices was included in the model in detail. In this logistic regression analysis, unprotected wet work was found to be associated with a significantly increased risk; at the same time risk estimates for the hairdressing attribute, which had contained all exposure-related effects in the previous model, declined to a considerable extent. However, the residual risk associated with the hairdressing attribute indicated that the internal reference group with "good skin protection" cannot be regarded as unexposed. (See the following discussion.)

Although the subjects' age was within a narrow range, a significant decline in risk was noted for older participants or, conversely, a significantly higher risk for younger apprentices (tabels 3 and 4). This interesting observation is open to interpretation: younger hairdressing apprentices possibly have an intrinsically more careless protective behavior or are less likely to insist on the availability of protective equipment (assuming that both aspects could not be represented sufficiently in the set of exposure variables). Although younger skin has been found to be more susceptible to irritation than older skin (13), this phenomenon may - within the range found in this study - not be contributory to the observed risk gradient.

Unprotected wet work could be demonstrated to be the major risk factor for irritant hand dermatitis. When compared with a reference group of hairdressing apprentices who worked unprotected with gloves for less than 2 hours and protected with gloves for more than 2 hours, the opposite profile entails an odds of about 1.8 to develop irritant hand dermatitis. Thus the earlier impression by Hornstein et al (5), that frequent wet work and insufficient skin protection are additional factors causing eczema, especially in atopic subjects, could be confirmed and quantified.

The risk estimates (odds ratios) may even underestimate the true importance of the exposure factors for several reasons, namely, the "dilution effect" induced by participants who started to wear protective gloves only after the appearance of skin changes being still present at the time of the examination (resulting in a combina- tion of the attributes "skin changes" and "good skin protection"). Furthermore, exposure misclassification resulting from the necessarily simplified questionnaire tool or due to the fact that some protective gloves were less protective against wet work hazards than others (eg, some polyethylene foil gloves being less protective than latex or vinyl gloves), a possiblity not taken into account in this study, leads to an underestimation of the exposure effects. In addition, the wearing of protective gloves does entail its own risk of (i) prolonged and repeated occlusion, which may be an irritant factor in its own right (14), and (ii) allergic contact dermatitis to glove material (eg, latex protein or rubber accelerators like thiurams) (15).

Even the group of hairdressing apprentices who protected their hands relatively well had an apparently increased risk. The odds of having skin changes at the end of training - even with good skin protection as operationalized in this study - was about 3 (except for the last phase) when the group was compared with the occupationally unexposed reference group of office apprentices (both time periods). Any base-line risk found will act as an important multiplicative factor for other (eg, constitutional or environmental) risk factors. This baseline risk may either be due to the fact that good protection does not completely eliminate the risk of skin irritation (or entails its own risk) or that the reference group ("good protection" within the fairly gross classification used) systematically or randomly includes persons with heavier exposure than assumed. A systematic error could have been introduced by the way the individual exposure was calculated (6); random error can be introduced by participants who state that they wear gloves but really do not protect themselves, and vice versa.

Interestingly, a significant decline in risk was noted for hairdressers when the last time period was compared with the first two time periods. This phenomenon may very cautiously be interpreted as a slight reduction of the general risk over time, in accordance with findings of another survey covering northwest Germany [employing a self-administered postal questionnaire without a medical examination (16)]. As skin protection (ie, the proportion of wet work performed with gloves) did not change between the time periods (data not shown) and was considered in the second multifactorial model (table 4), other factors have to be responsible for this observation, for example, increased dermatologic care (16). The participation of partially different observers in different time periods may principally be a reason for differences between the time periods. However, as most of the examinations were performed by the same observer, the potential distortion can be expected to be small. In addition, observer effects have been controlled for in the multifactorial model.

Unadjusted risk estimates have indicated a relatively low global risk (to show irritant skin damage or hand 
dermatitis at any time during the study examinations) in association with previous hand or flexural dermatitis, which are also relatively rare parameters (6). Consequently, only a small percentage of all cases of skin damage in the cohort would have been avoided if persons with these constitutional factors had not taken up hairdressing (6). This statement is probably only valid for this occupation - and most likely for other occupations with a similarly high irritant profile - and if a soft case definition is employed: the harder the case definition, the more important constitutional risk factors become (6) and the less intense the irritant strain is, the more pronounced the relative risk associated with atopic parameters appears to be (17).

Besides, the role of constitutional risk factors assessed in this multivariable analysis at the end of training is difficult to interpret. The decrease in prevalence of some of the risk factors (eg, past hand dermatitis, higher range of atopy score) in the group of hairdressing apprentices remaining in the cohort until the final examination suggests that the selective dropout of those with sensitive skin seriously hampered the evaluation of constitutional risk factors. In this context it has to be mentioned that, at an earlier stage of follow-up, at the end of the first year of training (with yet less dropout), past flexural eczema or a high atopy score were found to be significant risk factors in multivariable analyses similar to those presented in our study for the final follow-up (18). Other possible explanations for the lack of (significant) risk associated with these factors at that stage of the study are speculative and may include (i) increased awareness of skin-sensitive persons manifesting itself in efficient care that could not be represented in the model or (ii) different degrees of susceptibility to irritation even within the subgroup of crudely defined constitutionally sensitive persons.

Although point values of the atopy score should possibly not be overinterpreted, the score can be considered to be a gross ordinal scale measure of atopic parameters other than flexural eczema. The striking decline in risk in the highest category ( $>9.5$ points) could be explained as already discussed, particularly, as the highest category was strongly associated with previous hand or flexural dermatitis.

Such (self-) selection is mirrored in the external reference group of office apprentices. The prevalence of constitutional parameters was considerably higher in this group, which was only slightly older (median 19 years versus 17 years), and 5 of 111 participants were in a formal retraining program due to previous occupational skin disease. In addition, all the cases of more severe skin changes in this group were diagnosed as atopic hand eczema. Thus it seems that office work is taken up selectively by persons with sensitive skin who may have suffered from earlier episodes of (hand) dermatitis (9).
Work as a hairdresser entails a considerable risk of irritant hand dermatitis compared with, for example, virtually unexposed office work. This risk may be diminished, but not completely eliminated, by improved work conditions and skin protection (ie, the wearing of protective gloves for chemical work and for shampooing).

\section{Acknowledgments}

Without the cooperation of the vocational training schools in Bielefeld, Braunschweig, Bremen, Celle, Gütersloh, Hamburg, Hameln, Hannover, Lingen/Ems, Minden/Westfalen, Münster, Oldenburg, Osnabrück, Springe, and Wolfsburg this study would not have been possible. The following observers supported the corresponding author during the final follow-up examinations: B Bauch, SM John, M Nöhle, J Raguz, M Straube, R Weßbecher.

The work was supported by grant $376.3-46$ of the Employers Liability Insurance (Berufsgenossenschaft für Gesundheitsdienst und Wohlfahrtspflege, Hamburg)

\section{References}

1. Uter W, Gefeller O, Schwanitz HJ. Occupational dermatitis in hairdressing apprentices - early onset irritant skin damage. Curr Probl Dermatol 1995;23:49_55.

2. Cronin E, Kullavanijaya P. Hand dermatitis in hairdressers. Acta Dermatol Venerol [Stockh] 1979;59:47-50.

3. Shmunes E, Keil JE. Occupational dermatoses in South Carolina: a descriptive analysis of cost variables. $\mathbf{J}$ Am Acad Dermatol 1983;9:861-6.

4. Nilsson E, Mikaelsson B, Andersson S. Atopy, occupation and domestic work as risk factors for hand eczema in hospital workers. Contact Dermatitis 1985;13:216-23.

5. Hornstein OP, Bäurle G, Kienlein Kletschka B. Prospektivstudie zur Bedeutung konstitutioneller Parameter für die Ekzemgenese im Friseur- und Baugewerbe. Derm Beruf Umwelt 1985;33:43-9.

6. Uter W, Pfahlberg A, Gefeller O, Schwanitz HJ. Risk factors for hand dermatitis in hairdressing apprentices: results of the POSH-study. Derm Beruf Umwelt 1998;46:151-8.

7. Uter W, Gefeller O, Schwanitz HJ. An epidemiological study on the influence of Season (cold and dry air) on the occurrence of irritant skin changes of the hands. Br J Dermatol 1998;138:266-72.

8. Anonymus. TRGS 530. Technische Regeln für Gefahrstoffe 530. Bundesarbeitsblatt 1992;9:41-5.

9. Uter W, Pfahlberg A, Gefeller O, Schwanitz HJ. Hand eczema in a prospectively followed cohort of Office-Workers. Contact Dermatitis 1998;38:83-9.

10. Diepgen TL, Fartasch M, Hornstein OP. Kriterien zur Beurteilung der atopischen Hautdiathese. Derm Beruf Umwelt 1991;39:79-83.

11. Uter W, Pfahlberg A, Gefeller O, Schwanitz HJ. Prevalence 
and incidence of hand dermatitis in hairdressing apprentices: results of the POSH-study. Int Arch Occup Environ Health 1998;71:487-92.

12. Lemeshow S, Hosmer DW. The use of goodness-of-fit statistics in the development of logistic regression models. Am J Epidemiol 1982;115:92-106.

13. Patil S, Maibach HI. Effect of age and sex on the elicitation of irritant contact dermatitis. Contact Dermatitis 1994;30:25764.

14. Graves CJ, Edwards C, Marks R. The occlusive effect of protective gloves on the barrier properties of the stratum corneum. Curr Probl Dermatol 1995;23:87-94.

15. van der Walle HB, Brunsveld VM. Latex allergy among hairdressers. Contact Dermatitis 1995;32:177-8.
16. Schmidt U, Schwanitz HJ. Dermatosen bei Auszubildenden des Friseurhandwerks in Niedersachsen: Ein Vergleich zwischen 1989 und 1994. Derm Beruf Umwelt 1997;45:1215 .

17. Funke U, Diepgen TL, Fartasch M. Identification of high-risk groups for irritant contact dermatitis by occupational physicians. Curr Probl Dermatol 1995;23:64-72.

18. Uter W, Gefeller O, Schwanitz HJ. Einfluß von Hautempfindlichkeit und Arbeitsschutzmaßnahmen auf die Manifestation von Berufsekzemen bei Friseuren: Erste Ergebnisse einer prospektiven Kohortenstudie. Allergologie 1995;18:312 - 5.

Received for publication: 24 August 1998 